\title{
Chronic Sustained Hypoxia Enhances Both Evoked EPSCs and Norepinephrine Inhibition of Glutamatergic Afferent Inputs in the Nucleus of the Solitary Tract
}

\author{
Weirong Zhang, Flávia R. Carreño, J. Thomas Cunningham, and Steve W. Mifflin \\ Department of Pharmacology, The University of Texas Health Science Center at San Antonio, San Antonio, Texas 78229-3900
}

The nucleus of the solitary tract (NTS) receives inputs from both arterial chemoreceptors and central noradrenergic neural structures activated during hypoxia. We investigated norepinephrine (NE) modulation of chemoreceptor afferent integration after a chronic exposure to sustained hypoxia (CSH) (7-8 d at 10\% $\left.\mathrm{FIO}_{2}\right)$. Whole-cell recordings of NTS second-order neurons identified by DiA $\left(1,1^{\prime}-\right.$ dilinoleyl-3,3,3',3'-tetra-methylindocarbocyanine, 4-chlorobenzenesulphonate) labeling of carotid bodies were obtained in a brain slice. Electrical stimulation of the solitary tract was used to evoke EPSCs. CSH exposure increased evoked EPSC (eEPSC) amplitude via both presynaptic and postsynaptic mechanisms. NE dose dependently decreased the amplitude of eEPSCs. NE increased the paired-pulse ratio of eEPSCs and reduced the frequency of miniature EPSCs, suggesting a presynaptic mechanism. $\mathrm{EC}_{50}$ of NE inhibition of eEPSCs was lower in CSH cells $(3.0 \pm 0.9 \mu \mathrm{M} ; n=5)$ than in normoxic (NORM) cells $(7.6 \pm 1.0 \mu \mathrm{M} ; n=7 ; p<0.01)$. NE $(10 \mu \mathrm{M})$ elicited greater inhibition of eEPSCs in CSH cells $(63 \pm 2 \% ; n=16)$ than NORM cells $(45 \pm 3 \% ; n=21 ; p<0.01)$. The $\alpha$-adrenoreceptor antagonist phentolamine abolished NE inhibition of eEPSCs. CSH enhanced the $\alpha 2$-adrenoreceptor agonist clonidine-mediated inhibition ( $3 \mu \mathrm{M}$; NORM, $23 \pm 2 \%$, $n=5$ vs CSH, $44 \pm 5 \%, n=4 ; p<0.05)$ but attenuated $\alpha 1$-adrenoreceptor agonist phenylephrine-mediated inhibition ( $40 \mu \mathrm{m}$; NORM, $36 \pm 2 \%, n=11$ vs $\mathrm{CSH}, 26 \pm 4 \%, n=6 ; p<0.05)$. The $\alpha 2$-adrenoreceptor antagonist yohimbine abolished CSH-induced enhancement of NE inhibition of eEPSCs. These results demonstrate that CSH increases evoked excitatory inputs to NTS neurons receiving arterial chemoreceptor inputs. CSH also enhances NE inhibition of glutamate release from inputs to these neurons via presynaptic $\alpha 2$ adrenoreceptors. These changes represent central neural adaptations to $\mathrm{CSH}$.

\section{Introduction}

During many pathophysiological conditions, periods of general or focal brain ischemia/hypoxia occur that can result in neuronal injury and interruption of synaptic transmission as well as a dramatic change in the extracellular concentration of various neurochemicals (Lipton, 1999). In particular, excessive extracellular glutamate may have an excitotoxic effect depending on the severity of the tissue hypoxia. At the same time, other neurochemicals are released to counteract the toxic glutamate effect by depressing excitatory synaptic transmission and reducing glutamate release. One such neurochemical is norepinephrine (NE), and NE levels increase dramatically in mammalian brain and spinal cord during hypoxia (Globus et al., 1989; Perego et al., 1992; Nakai et al., 1999).

A unique scenario occurs in the central pathways that mediate arterial chemoreflexes. These neural structures experience tissue hypoxia during acute or chronic hypoxia. However, synaptic transmission of chemoreceptor afferent inputs has to be sus-

\footnotetext{
Received June 10, 2008; revised Jan. 21, 2009; accepted Feb. 2, 2009.

This work was supported by National Heart, Lung, and Blood Institute Grants HL-41894 (S.W.M.) and HL-62579 (J.T.C.). We acknowledge the assistance of Myrna Herrera-Rosales and Melissa Vitela.

Correspondence should be addressed to Dr. Steve W. Mifflin, Department of Pharmacology, MSC 7764, The University of Texas Health Science Center at San Antonio, 7703 Floyd Curl Drive, San Antonio, TX 78229-3900. E-mail: mifflin@uthscsa.edu.

D01:10.1523/JNEUROSCI.2648-08.2009

Copyright $\odot 2009$ Society for Neuroscience $\quad 0270-6474 / 09 / 293093-10 \$ 15.00 / 0$
}

tained to maintain the reflex response to hypoxia, i.e., increased sympathetic nerve activity and respiratory activity (Guyenet, 2000). The nucleus of the solitary tract (NTS) receives the first central projections of the arterial chemoreceptors and is the first central integration site in arterial chemoreflex pathways (Loewy, 1990; Mifflin, 1992). The NTS contains its own noradrenergic neurons the A2 cell group and also receives inputs from multiple central noradrenergic structures (Loewy, 1990).

The $\alpha 1$-, $\alpha 2$-, and $\beta$-adrenoreceptor subtypes have been detected in the NTS (Young and Kuhar, 1980; Dashwood et al., 1985; Jones et al., 1985; Aoki et al., 1989; Day et al., 1997). Microinjection of NE into the NTS attenuated cardiovascular responses in both arterial chemoreflex and arterial baroreflex (De Jong, 1974; Silva de Oliveira et al., 2007). Additional evidence suggests that activation of both $\alpha 1$ - and $\alpha 2$-adrenoreceptors has inhibitory effect in the NTS (Moore and Guyenet, 1983; Feldman and Moises, 1987, 1988; Feldman and Felder, 1989a,b; Zhang and Mifflin, 2007), although the contribution of different adrenoreceptor subtypes is still unknown.

Chronic sustained hypoxia $(\mathrm{CSH})$ is a pathophysiological situation associated with chronic pulmonary and heart disease and travel to high altitude. $\mathrm{CSH}$ alters the neural control of cardiorespiratory activity (Powell et al., 2000; Prabhakar and Jacono, 2005). Whether CSH induces adaptive changes in synaptic integration of arterial chemoreceptor inputs in the NTS has not been investigated. We report that CSH enhances glutamatergic synap- 
tic transmission of arterial chemoreceptor inputs in the NTS via presynaptic and postsynaptic mechanisms. In addition, $\mathrm{CSH}$ has been shown to induce significant changes in NE metabolism in the NTS and in other noradrenergic structures that project to the NTS (Soulier et al., 1992; Schmitt et al., 1994). Whether CSH alters NE modulation of synaptic transmission within the NTS is currently unknown. Our results show that CSH enhances NEmediated, $\alpha 2$-adrenoreceptor inhibition of glutamate release within the NTS.

\section{Materials and Methods}

All experimental protocols were approved by the Institutional Animal Care and Use Committee at the University of Texas Health Science Center at San Antonio.

Surgical preparation for labeling carotid body. All experiments were performed on male Sprague Dawley rats (125-145 g; Charles River Laboratories). Rats were anesthetized with a combination of ketamine (75 mg/kg, i.p.) and medetomidine ( $0.5 \mathrm{mg} / \mathrm{kg}$, i.p.; Pfizer). Crystals of anterograde fluorescent dye 1,1'-dilinoleyl-3,3,3',3'-tetramethylindocarbocyanine, 4-chlorobenzenesulphonate (DiA) were applied unilaterally to the carotid body region to visualize the chemoreceptor synaptic terminals in the NTS and neurons receiving these synaptic contacts (Tolstykh et al., 2004; de Paula et al., 2007; Zhang and Mifflin, 2007; Zhang et al., 2008). The area was then embedded with silicone adhesive (Kwik-Sil; WPI). Anesthesia was terminated by atipamezole (1 $\mathrm{mg} / \mathrm{kg}$, i.p.; Pfizer), and postoperative analgesics (nubaine, intramuscularly) were available.

Chronic hypoxia exposure. Rats were divided into two groups: $\mathrm{CSH}$ group and normoxic control (NORM) group. CSH rats were housed in their home cages within a normobaric hypoxia chamber at oxygen levels of $10 \pm 0.5 \%$ for $7-8 \mathrm{~d}$ as described previously (Ilyinsky et al., 2003; Tolstykh et al., 2004; Ilyinsky and Mifflin, 2005; Zhang et al., 2008). The air within the chamber was recycled, and the oxygen level was controlled by a computer-driven set of valves and pumps. A hypoxic environment was achieved by the addition of nitrogen gas to room air. Oxygen levels within the chamber were monitored with an electrochemical sensor, and this information fed into the computer-driven feedback circuit so that deviations in the oxygen level from preset value were rapidly corrected by adding appropriate gas. Temperature and humidity were monitored, and the recycled air was passed through a desiccant and $\mathrm{CO}_{2}$ scrubber (soda lime) to maintain normal humidity and $\mathrm{CO}_{2}$ levels within the chamber. NORM rats were maintained in a similar environment while breathing room air.

Brain slice preparation. Anesthesia was induced with isoflurane, and the brainstem was rapidly removed and placed in ice-cold, high-sucrose, artificial CSF (aCSF) that contained the following (in $\mathrm{mm}$ ): $3 \mathrm{KCl}, 1$ $\mathrm{MgCl}_{2}, 1 \mathrm{CaCl}_{2}, 2 \mathrm{MgSO}_{4}, 1.25 \mathrm{NaH}_{2} \mathrm{PO}_{4}, 26 \mathrm{NaHCO}_{3}, 10$ glucose, and 206 sucrose, $\mathrm{pH} 7.4$ (when continuously bubbled with $95 \% \mathrm{O}_{2} / 5 \% \mathrm{CO}_{2}$ ). The brainstem was mounted in a vibrating microtome (VT1000E; Leica Microsystems), and horizontal slices ( $250 \mu \mathrm{m}$ thickness) were cut with a sapphire knife (Delaware Diamond Knives). The slices were incubated for at least $1 \mathrm{~h}$ in normal aCSF that contained the following (in mM): 124 $\mathrm{NaCl}, 3 \mathrm{KCl}, 2 \mathrm{MgSO}_{4}, 1.25 \mathrm{NaH}_{2} \mathrm{PO}_{4}, 26 \mathrm{NaHCO}_{3}, 10$ glucose, and 2 $\mathrm{CaCl}_{2}$, pH 7.4 (when continuously bubbled with $95 \% \mathrm{O}_{2} / 5 \% \mathrm{CO}_{2}$ ).

Electrophysiological recording. Whole-cell patch-clamp recordings were performed in the recording chamber on an upright epifluorescent microscope (BX50WI; Olympus) equipped with infrared differential interference contrast and an optical filter set for visualization of DiA. The slice was held in place with a nylon mesh, submerged in normal aCSF equilibrated with $95 \% \mathrm{O}_{2} / 5 \% \mathrm{CO}_{2}$, and perfused at a rate of $2-3 \mathrm{ml} / \mathrm{min}$. All images were captured with a charge-coupled device (CCD) camera (IR-1000, CCD-100; Dage-MTI) displayed on a television monitor and stored on a personal computer. Patch pipettes were pulled from borosilicate glass capillaries with an inner filament $(0.90 \mathrm{~mm}$ inner diameter, 1.2 $\mathrm{mm}$ outer diameter; WPI) on a pipette puller (model P-2000; Sutter Instruments) and were filled with a solution that contained the following (in mM): $145 \mathrm{~K}$-gluconate, $1 \mathrm{MgCl}_{2}, 10 \mathrm{HEPES}, 1.1 \mathrm{EGTA}, 2 \mathrm{Mg}_{2} \mathrm{ATP}$, and $0.3 \mathrm{Na}_{3} \mathrm{GTP}$. The $\mathrm{pH}$ was adjusted to 7.3 with $\mathrm{KOH}$. The pipette resis- tance ranged from 3 to $6 \mathrm{M} \Omega$. A seal resistance of at least $1 \mathrm{G} \Omega$ or above and an access resistance $<20 \mathrm{M} \Omega$ that changed $<15 \%$ during recording were considered acceptable. Series resistance was optimally compensated. Recordings of postsynaptic currents began $5 \mathrm{~min}$ after the wholecell access was established and the holding current reached a steady state. Recordings were made with an AxoPatch 200B patch-clamp amplifier and pClamp software version 8 (Molecular Devices). Whole-cell currents were filtered at $2 \mathrm{kHz}$, digitized at $10 \mathrm{kHz}$ with the DigiData 1200 Interface (Molecular Devices), and stored in a personal computer for offline analysis. All experiments were performed at room temperature.

Whole-cell voltage-clamp recordings were performed on secondorder NTS arterial chemoreceptor neurons labeled with fluorescent DiA (Fig. 1 A). Cells were clamped at a membrane potential of $-60 \mathrm{mV}$. Input resistance was monitored by frequently applying a $10 \mathrm{mV}$ hyperpolarizing voltage step ( $100 \mathrm{~ms}$ duration) from a holding potential of $-60 \mathrm{mV}$. Evoked EPSCs (eEPSCs) were elicited by electrical stimulation of the ipsilateral solitary tract (ST) using a concentric bipolar electrodes (FHC) with a tip diameter of $200 \mu \mathrm{m}$. Square electric pulses of $0.1 \mathrm{~ms}$ duration with a frequency of $0.2 \mathrm{~Hz}$ were delivered through a stimulus isolator A360 (WPI), in series with a programmable stimulator (Master8; A.M.P.I.). All data were collected while the ST was stimulated at $2.5 \times$ threshold that was defined as the lowest stimulation intensity to reliably evoke monosynaptic EPSCs. Recordings of glutamatergic EPSCs were performed in the presence of the $\mathrm{GABA}_{\mathrm{A}}$ receptor antagonist gabazine $(25 \mu \mathrm{M})$. Bath application of drugs typically lasted $\sim 3-5 \mathrm{~min}$ to achieve steady state and begin drug effect tests.

When testing frequency-dependent depression of eEPSCs, a train of 30 stimuli was delivered to ST at frequencies of $0.2,1,3,10$, and $20 \mathrm{~Hz}$. The last 20 responses in each train were averaged. A paired-pulse stimulation protocol was used as one means of identifying potential presynaptic mechanism. Two synaptic responses (A1 and A2) were evoked by a pair of stimuli given at an interval ranging from 20 to $200 \mathrm{~ms}$. Paired-pulse ratio (PPR) was calculated as the amplitude ratio of the second synaptic response to the first synaptic response (A2/A1). A second analysis of presynaptic effects involved examination of miniature EPSCs (mEPSCs). The mEPSCs were recorded in the presence of the sodium channel blocker tetrodotoxin (TTX) $(1 \mu \mathrm{M})$ and the $\mathrm{GABA}_{\mathrm{A}}$ receptor antagonist gabazine $(25 \mu \mathrm{M})$. At least 200 miniature events were collected before and during drug application and $15 \mathrm{~min}$ after washout.

Puff drug application. Puff application of glutamate (1 mM) was performed by using a syringe pump delivery system (model 310; Stoelting). Glutamate was delivered from a patch pipette $(\sim 10 \mu \mathrm{m}$ tip diameter, 10 $\mathrm{nl}$ volume, $0.5 \mathrm{~s}$ injection duration) positioned $\sim 25 \mu \mathrm{m}$ from the recorded neuron to elicit a reproducible postsynaptic response. Postsynaptic responses were recorded at a holding potential of $-60 \mathrm{mV}$ in the presence of $1 \mu \mathrm{M}$ TTX, $300 \mu \mathrm{M}$ picrotoxin, and $100 \mu \mathrm{M}$ DL-2-amino-5phosphonovaleric acid (AP-5). In control studies, injection of the same volume of aCSF did not elicit significant changes in holding current $(n=$ 4; data not shown), indicating minimal mechanical disturbance by our puff application method.

Western blot analysis. Each rat was anesthetized with isoflurane and decapitated. The brain was removed from the skull, and the brainstem was placed in a commercially available brain matrix (Stoelting). The brainstem was then cut into 1-mm-thick coronal sections with razor blades. Under a dissecting microscope, the caudal NTS was dissected from the sections, placed in microcentrifuge tubes, and flash frozen with liquid nitrogen. The caudal NTS was then sonicated in $50 \mu \mathrm{l}$ of modified radioimmunoprecipitation assay buffer supplemented with protease and phosphatase inhibitors (Sigma), followed by $30 \mathrm{~min}$ incubation on ice. The total homogenate was then centrifuged at $4^{\circ} \mathrm{C}$ for $30 \mathrm{~min}$ at 14,000 $\mathrm{rpm}$, and the total protein for each sample was determined by the Bradford method. Six $\mu \mathrm{g}$ (GluR1) or $12 \mu \mathrm{g}$ (GluR2) of the cleared total lysate was loaded onto $10 \%$ acrylamide SDS gel, electrophoresed in Tris-glycine buffer under denaturing conditions, and transferred to nitrocellulose membrane (Bio-Rad) in Tris-glycine buffer with 20\% methanol. Membranes were blocked for $1 \mathrm{~h}$ at room temperature with $5 \%$ nonfat milk in Tris-buffered saline-Tween 20 (TBS-Tween) (50 mм Tris base, $200 \mathrm{~mm} \mathrm{NaCl}$, and $0.1 \%$ Tween 20 ) and then incubated overnight at $4^{\circ} \mathrm{C}$ with primary antibodies against AMPA receptor subunit GluR1 and 
A
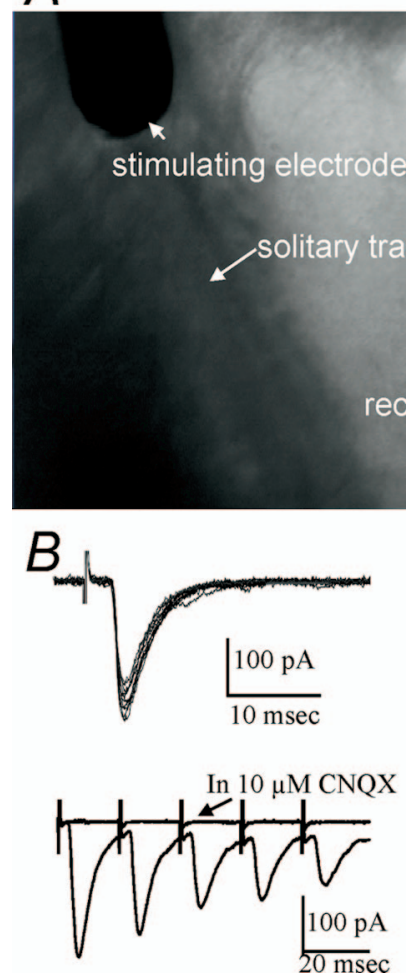

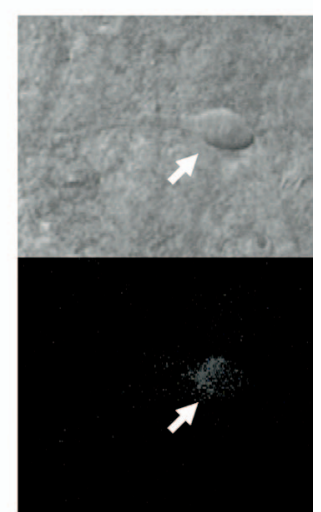

C

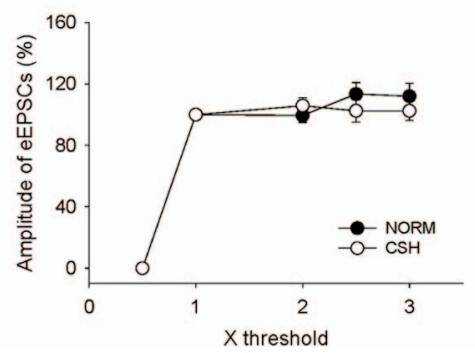

Figure 1. Second-order neurons of arterial chemoreceptor reflex in horizontal NTS slice. $\boldsymbol{A}$, Whole-cell patch-clamp recording from a second-order peripheral chemoreceptor neuron in the NTS. The left photograph shows the position of the stimulating electrode covering the solitary tract and recording site at the tip of a recording pipette within the NTS. The cell indicated by the arrow in the top right photograph (infrared differential contrast) was labeled with DiA when viewed with fluorescence set (bottom right photograph). $\boldsymbol{B}$, Top is an example of 10 superimposed sweeps of eEPSCs. Notice very low variability in onset latency of the eEPSCs. Bottom is an example of frequency-dependent depression in the same neuron. The eEPSCs were evoked by a train of five solitary tract stimuli at $20 \mathrm{~ms}$ interval, and the sweep represents the average of 10 such stimulation cycles. Note the reduction in the amplitude of successive eEPSCs during train stimulation. The top sweep illustrates that eEPSCs were abolished by superfusion of the slice with the non-NMDA receptor antagonist CNQX. C, The amplitude of the eEPSC (presented as a percentage of the amplitude at threshold) as a function of tractus stimulation intensity (presented as a multiple of threshold). Note that the eEPSC is an all-or-none response in both NORM $(n=5)$ and CSH $(n=6)$ NTS neurons.

GluR2 (both at 1:1000; Calbiochem) or $\beta$-actin (1:600; Sigma). Blots were rinsed three times, 10 min each with TBS-Tween and then incubated at room temperature for $1 \mathrm{~h}$ in a horseradish peroxidaseconjugated secondary antibody against respective primary antibody host species (1:5000; Sigma). The respective immunoreactive bands were detected by enhanced chemiluminescence (ECL reagents; GE Healthcare) and exposed to radiographic film (Hyperfilm ECL; GE Healthcare).

Data analysis. Data are presented as mean \pm SEM. Peak amplitudes of averaged evoked postsynaptic currents ( $\geq 10$ sweeps) were calculated as the difference from the baseline measured several milliseconds before the stimulation artifact. Differences in drug effects were tested by ANOVA or $t$ test. All miniature events were detected with MiniAnalysis software (version 6.0; Synaptosoft). The threshold value for detecting mEPSCs was set as four times the root-mean-square baseline noise, and all miniature events detected by the software were visually checked to minimize errors. Cumulative distributions of miniature synaptic current amplitudes and frequencies were compared using Kolmogorov-Smirnov $(\mathrm{K}-\mathrm{S})$ test nonparametric analysis. For Western blot analysis, the immunoreactive bands of interest were quantified by densitometry using the Scion program, and the respective values were normalized against $\beta$-actin densitometry. Data were expressed as arbitrary densitometric units. Statistical tests were performed with SigmaStat (version 2.03; SPSS Inc.), and graphs were made in SigmaPlot (version 8.0; SPSS Inc.). Values of $p<0.05$ were considered significant.

Drugs. DiA was obtained from Invitrogen. Gabazine (SR 95531 hydrobromide) was obtained from Tocris Cookson. AP-5, (R)-(-)- phenylephrine $\mathrm{HCl}$, yohimbine $\mathrm{HCl}$, 6-cyano7-nitroquinoxaline-2,3-dione (CNQX), $( \pm)$ propranolol $\mathrm{HCl}, \mathrm{L}(-)$-norepinephrine bitartrate, clonidine $\mathrm{HCl}$, and other chemicals were obtained from Sigma. To protect NE from degradation, all buffers included the antioxidant sodium metabisulfite $(10 \mu \mathrm{M})$, and solutions were prepared freshly before the experiment and protected from bright light.

\section{Results}

All data were obtained from second-order neurons in the NTS, identified by the presence of DiA-labeled somatic appositions as shown in Figure $1 \mathrm{~A}$. Whole-cell patchclamp recordings were performed on 201 DiA-labeled NTS cells from 69 NORM rats and $49 \mathrm{CSH}$ rats.

\section{CSH alters glutamatergic synaptic transmission in the NTS}

There was no statistical difference between NORM $(n=113)$ and CSH $(n=88)$ neurons in resting membrane potential (NORM, $-55.5 \pm 0.4 \mathrm{mV}$; CSH, $-56.0 \pm$ $0.5 \mathrm{mV}$ ) and input resistance (NORM, $1.00 \pm 0.05 \mathrm{G} \Omega ; \mathrm{CSH}, 1.06 \pm 0.07 \mathrm{G} \Omega$ ).

Electrical stimulation of the solitary tract evoked EPSCs in second-order neurons of arterial chemoreceptors in the NTS when GABAergic inputs were blocked with gabazine (Fig. $1 B$ ). The variability of onset latencies, as calculated from the SD of the response onset latency from 10 sweeps, was $<200 \mu$ s (median value, 88 $\mu \mathrm{s}$ ), further suggesting a monosynaptic input from afferent terminals (Doyle and Andresen, 2001; Zhang and Mifflin, 2007). The eEPSCs were mediated by activation of non-NMDA receptors because the nonNMDA receptor antagonist CNQX (10 $\mu \mathrm{M}$ ) abolished eEPSCs (Fig. $1 B$ ) (Zhang and Mifflin, 2007, their Fig. 1). Similar to findings from others (Bailey et al., 2006), eEP$\mathrm{SCs}$ elicited from the tractus were all-or-none responses. Additional increases in stimulation intensity above threshold did not change the onset latency or amplitude of the evoked responses. There was no difference in the threshold stimulation intensity (NORM, $104 \pm 5 \mu \mathrm{A}$ vs CSH, $101 \pm 9 \mu \mathrm{A} ; p>0.05)$ or the all-or-none nature of the eEPSC comparing NORM and CSH rats (Fig. 1C).

The maximal amplitude of eEPSCs was significantly greater in CSH than in NORM neurons $(296.5 \pm 20.4 \mathrm{pA}, n=76$ vs $220.7 \pm$ $13.2 \mathrm{pA}, n=92$; $p<0.01$ ) (Fig. $2 A, B$ ). A separate group of rats were allowed to recover from exposure to $\mathrm{CSH}$ by remaining in room air for $7 \mathrm{~d}$ after CSH treatment. The amplitude of eEPSCs in these recovered rats was not significantly different from that observed in NORM rats (recovery, $185.5 \pm 15.3 \mathrm{pA} ; n=10$ ). Onset latency of the eEPSC was not affected by CSH (NORM, $4.9 \pm 0.2$ $\mathrm{ms}$ vs $\mathrm{CSH}, 4.7 \pm 0.2 \mathrm{~ms}$ vs recovery, $4.9 \pm 0.5 \mathrm{~ms})$. We next investigated potential presynaptic and/or postsynaptic mechanisms underlying $\mathrm{CSH}$-induced enhancement of the eEPSC.

We first examined the postsynaptic currents elicited by direct puff application of $1 \mathrm{~mm}$ glutamate in the presence of $\mathrm{GABA}_{\mathrm{A}}$ and 
NMDA receptor blockade in NTS neurons from both NORM and CSH rats (Fig. 2C). The glutamate-evoked inward current in DiA-labeled NTS neurons was significantly greater in CSH than in NORM neurons $(127.8 \pm 23.5 \mathrm{pA}, n=9$ vs $55.3 \pm$ $16.8 \mathrm{pA}, n=8 ; p<0.05)$. Western blot analysis of the caudal NTS indicated an increased level of GluR2 subunit in the NTS of $\mathrm{CSH}$ rats $(266 \%$ increase compared with NORM rats; both $n=5$ ) (Fig. 2D). There was no significant difference in the level of GluR1 subunit comparing CSH with NORM rats (Fig. 2D).

Frequency-dependent depression of visceral afferent inputs in the NTS has been proposed to optimize information transfer within central networks (Miles 1986; Glaum and Miller, 1995; Schild et al., 1995; Scheuer et al., 1996; Chen et al., 1999; Doyle and Andresen, 2001). This phenomenon is considered to be primarily mediated by presynaptic mechanisms and related to neurotransmitter release probability (Zucker and Regehr, 2002).A solitary tract stimulation frequency of $0.2 \mathrm{~Hz}$ was chosen as the control because there was no significant change in eEPSC amplitude during stimulation at this frequency (Figs. $1 B, 2 E$ ). The amplitudes of eEPSCs decreased as the frequency of ST stimulation increased. $\mathrm{CSH}$ attenuated frequencydependent depression of eEPSCs (Fig. $2 E)$.

We further examined alterations in presynaptic glutamate release in the NTS by analyzing action potential-independent spontaneous glutamate release from presynaptic terminals, mEPSCs. The bath solution included gabazine $(25 \mu \mathrm{M})$ to block $\mathrm{GABA}_{\mathrm{A}}$ receptors and the sodium channel blocker TTX $(1 \mu \mathrm{M})$. The mEPSCs were glutamatergic in origin because they were completely abolished by the non-NMDA receptor antagonist CNQX $(10 \mu \mathrm{M})$ (data not shown). The frequency of mEPSCs in $\mathrm{CSH}$ neurons $(1.83 \pm 0.26 \mathrm{~Hz})$ was significantly less than that observed in NORM neurons $(3.62 \pm 0.59 \mathrm{~Hz} ; p<0.05)$ (Fig. $2 G, H)$. There was no difference in the amplitude of mEPSCs between CSH neurons and NORM neurons (CSH, $28.0 \pm 3.0 \mathrm{pA}$, $n=11$ vs NORM, $26.7 \pm 2.3 \mathrm{pA}, n=12$; $p>0.05)$ (Fig. $2 H$ ).

These data indicate that $\mathrm{CSH}$ exposure increases both glutamate release probability and the postsynaptic response to glutamate, resulting in enhanced glutamatergic synaptic transmission of arterial chemoreceptor inputs in the NTS.

\section{CSH enhances NE-mediated inhibition of eEPSCs}

Bath application of $10 \mu \mathrm{M}$ NE reduced the amplitude of eEPSCs without a significant change in onset latency in both NORM and
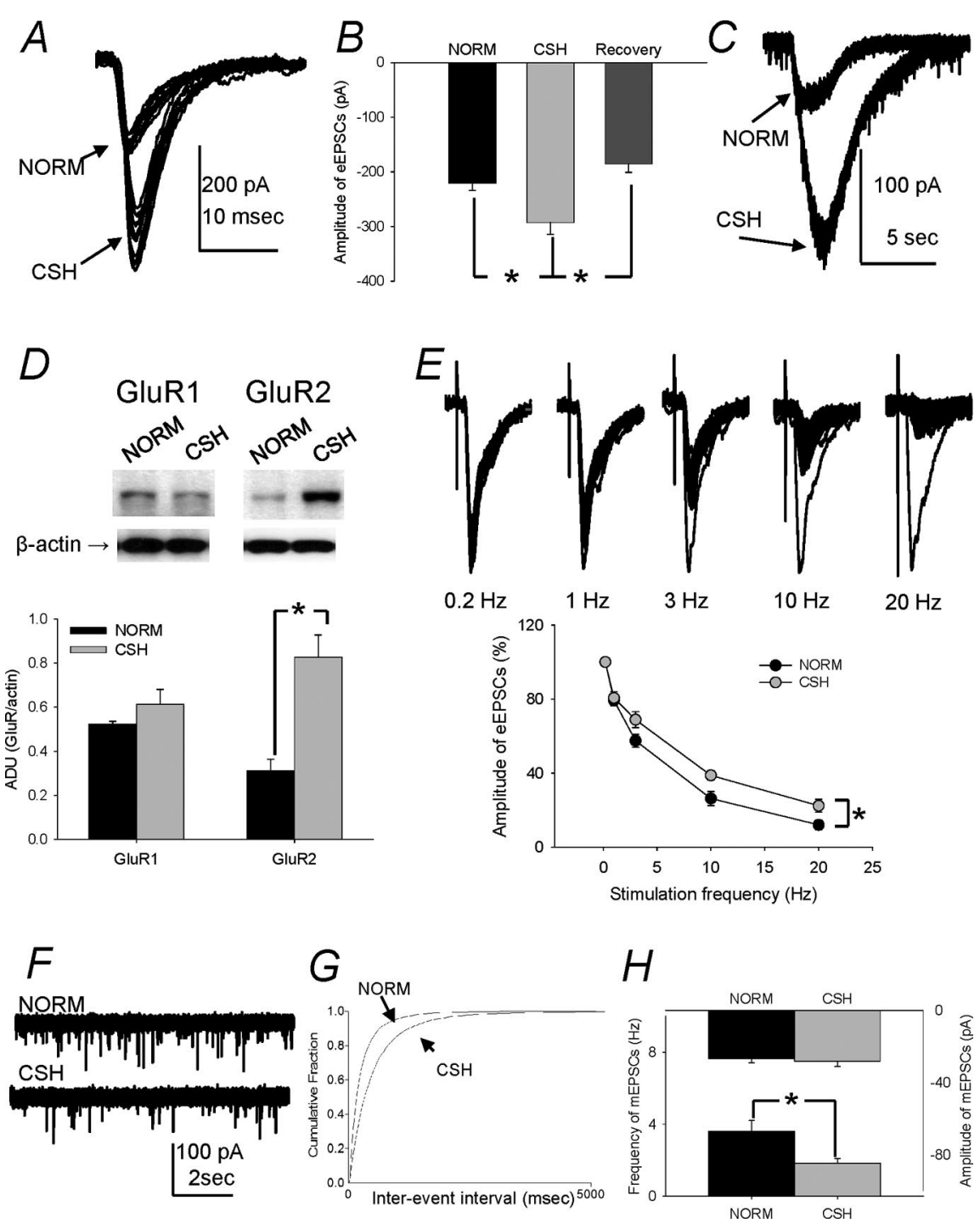

Figure 2. Chronic hypoxia enhances eEPSCs elicited by tractus stimulation. $\boldsymbol{A}$, Raw data showing typical eEPSCs recorded from a CSH neuron and a NORM neuron. The responses of each neuron to 10 solitary tract stimuli are illustrated. $B$, Group data showing that eEPSCs amplitude was significantly greater in CSH neurons than in NORM neurons (NORM, $n=92$ vs CSH, $n=76 ; p<0.01$ ). One week after exposure to CSH, eEPSCs amplitude was not different from that observed in NORM neurons (Recovery, $n=10$ ). C, Raw data showing typical inward current elicited by puff application of $1 \mathrm{~mm}$ glutamate on CSH and NORM neurons. Postsynaptic response to direct glutamate application is greater in $\mathrm{CSH}$ neurons than that in NORM neurons. The recording is in the presence of $300 \mu \mathrm{M} \mathrm{GABA}_{\mathrm{A}}$ receptor antagonist picrotoxin and $100 \mu \mathrm{M}$ NMDA receptor antagonist AP-5. D, Raw data showing the Western blot results for AMPA receptor subunits GluR1 and GluR2. Group data showing the increase in GluR2, but not GluR1, subunits in the NTS of CSH rats compared with NORM rats (both $n=5 ;{ }^{*} p<0.01$ for GluR2). $E$, Raw data showing 30 superimposed eEPSCS evoked by different solitary tract stimulation frequencies. At stimulus frequencies of $3-20 \mathrm{~Hz}$, the single large-amplitude eEPSC is the first one evoked by the train. Group data showing attenuated frequency-dependent depression of eEPSCs in CSH $(n=7)$ compared with NORM $\left(n=10 ;{ }^{*} p<0.05\right)$. $\boldsymbol{F}$, Raw data showing two representative recordings of $m E$ EPSCs from NORM and CSH neurons. All data were collected in the presence of $\mathrm{GABA}_{\mathrm{A}}$ receptor antagonist gabazine $(25 \mu \mathrm{M})$ and sodium channel blocker TTX $(1 \mu \mathrm{M}) . \mathbf{G}$, The cumulative probability of the mEPSC interevent interval was shifted rightward to smaller frequencies in CSH compared with NORM NTS neurons ( $K-S$ test, $p<0.05$ ). $\boldsymbol{H}$, Group data showing the average frequency of $m$ EPSC $\sin$ CSH neurons (bottom bars in histogram; $n=11$ ) was significantly smaller than NORM neurons $(n=12 ; p<0.05)$. There was no difference in amplitude of mEPSCs (top bars in histogram) between the two groups.

CSH neurons (Fig. 3A). In CSH neurons, NE-mediated inhibition of eEPSCs was enhanced compared with NORM neurons. In cells in which all doses of $\mathrm{NE}$ were tested, the $\mathrm{EC}_{50}$ of the $\mathrm{NE}$ inhibition of eEPSCs was less in CSH neurons $(3.0 \pm 0.9 \mu \mathrm{M} ; n=$ 5) than in NORM neurons (7.6 $\pm 1.0 \mu \mathrm{M} ; n=7 ; p<0.01$ ) (Fig. $3 B)$. At a concentration of $10 \mu \mathrm{M}, \mathrm{NE}$ caused greater inhibition of eEPSCs in CSH neurons than in NORM neurons $(63 \pm 2 \%, n=$ 9 vs $45 \pm 3 \%, n=8 ; p<0.01)$. 

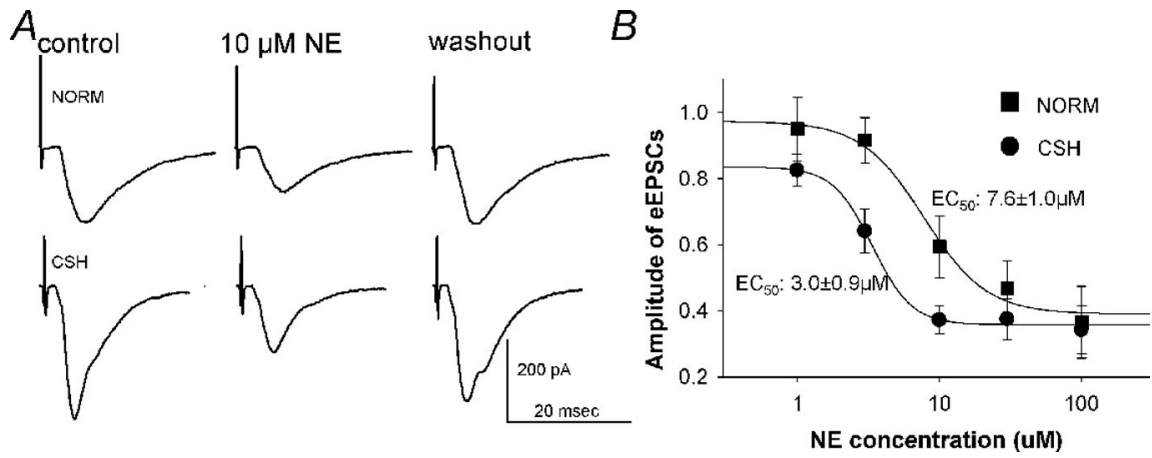

Figure 3. NE inhibits tractus evoked EPSCS. A, Raw data showing the inhibitory effect of $10 \mu \mathrm{m}$ NE on eEPSCs in both NORM and CSH neurons. Corresponding inhibitory ratio was 58 and $51 \%$, respectively. Note that there is no discernable change in holding current during application of NE. $B$, The $\mathrm{EC}_{50}$ of NE inhibition of eEPSCs was significantly less in CSH $(n=5)$ compared with NORM $(n=7)$ neurons.

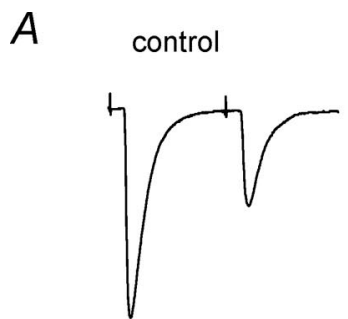

$B$

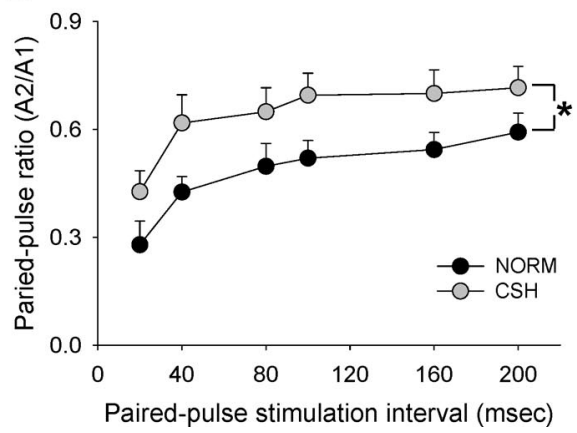

$10 \mu \mathrm{MNE}$

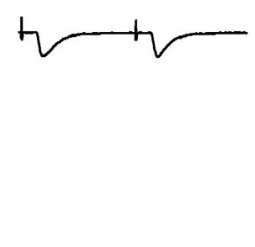

C

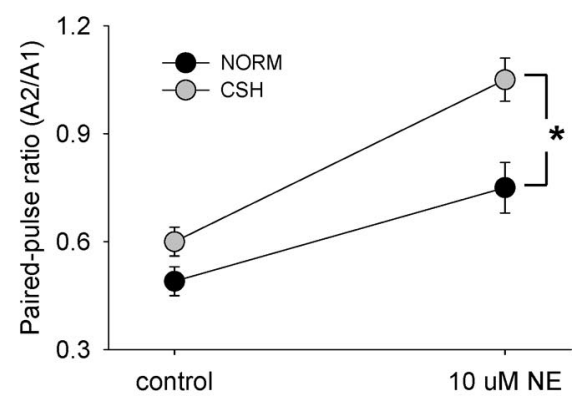

Figure 4. NE modulates paired-pulse stimulation response. $A$, Raw data showing that $10 \mu \mathrm{m}$ NE increased the PPR of eEPSCs in a second-order NTS neuron. $\boldsymbol{B}$, There is significant difference in PPRs between NORM and CSH neurons at pulse intervals ranging from 20 to $200 \mathrm{~ms}$ (both $n=6 ; p<0.05$ ). C, Application of $10 \mu \mathrm{m} \mathrm{NE} \mathrm{significantly} \mathrm{increased} \mathrm{the} \mathrm{PPR} \mathrm{of} \mathrm{eEPSCs} \mathrm{at} \mathrm{the} \mathrm{pulse} \mathrm{interval}$ of $40 \mathrm{~ms}$ in both NORM $(n=13)$ and CSH $(n=10)$ neurons, but the increase was greater in CSH neurons than in NORM neurons. ${ }^{*} p<0.05$.

In most second-order neurons, there was no discernable change in holding current and input resistance during application of $10 \mu \mathrm{M} \mathrm{NE}$, suggesting that the primary site of NE inhibition is presynaptic. In cells with a postsynaptic response, $10 \mu \mathrm{M}$ NE induced outward currents of $18.3 \pm 3.6 \mathrm{pA}$ in NORM neurons ( 9 of 53) and $15.3 \pm 3.2 \mathrm{pA}$ in CSH neurons (5 of 29) and a decrease in input resistance of $51 \pm 4 \%$ in NORM neurons and $51 \pm 7 \%$ in CSH neurons. No significant difference in the postsynaptic response to NE was observed between NORM and $\mathrm{CSH}$ neurons that exhibited a postsynaptic response to NE.

\section{CSH enhances NE increase of paired-pulse ratio}

To further investigate the presynaptic effect of NE, we examined paired-pulse stimulation responses. A change in PPR (the ratio of second evoked response amplitude to the amplitude of the first evoked response) indicates a presynaptic site of action (Zucker and Regehr, 2002). NE (10 $\mu \mathrm{M})$ increased PPR (Fig. 4A), supporting a presynaptic site for NE inhibition of eEPSCs. The PPR was significantly increased in $\mathrm{CSH}$ neurons compared with NORM neurons ( $p<$ $0.01)$ (Fig. $4 B)$. NE $(10 \mu \mathrm{M})$ significantly increased PPR at a pulse interval of $40 \mathrm{~ms}$ $(p<0.001)$ in both NORM and CSH neurons (Fig. 4C). However, the increase was greater in CSH neurons than in NORM neurons $(180 \pm 11 \%, n=10$ vs $150 \pm 8 \%$, $n=13 ; p<0.05)$.

\section{NE inhibition of mEPSCs}

We further examined alterations in NE inhibition of presynaptic glutamate release in the NTS by recording action potentialindependent spontaneous glutamate release from presynaptic terminals (mEPSCs). The bath solution included $25 \mu \mathrm{M}$ gabazine to block $\mathrm{GABA}_{\mathrm{A}}$ receptors and 1 $\mu \mathrm{M}$ sodium channel blocker TTX to record mEPSCs. NE $\left(\begin{array}{lll}10 & \mu \mathrm{M}\end{array}\right)$ significantly reduced the frequency of mEPSCs in both $\mathrm{CSH}$ neurons and NORM neurons $(p<$ 0.001 ) but not the amplitude of mEPSCs (Fig. 5). As previously discussed, the frequency of mEPSCs was reduced after exposure to CSH. However, there was no difference in NE inhibition of mEPSC frequency comparing NORM (44.0 \pm $5.5 \% ; n=7)$ with CSH $(44.9 \pm 5.0 \% ; n=$ $8 ; p>0.05$ ) neurons (Fig. $5 B$ ).

\section{NE effect in the NTS is mediated} primarily by $\alpha$-adrenoreceptors

To determine which adrenoreceptors mediate NE inhibition of glutamate release in the NTS, we applied NE (10 $\mu \mathrm{M})$ alone and in combination with an adrenoreceptor antagonist (Fig. 6A). There was no significant difference in the inhibition of eEPSCs between two repeated applications separated by $15 \mathrm{~min}$ of $10 \mu \mathrm{M}$ NE alone (57 \pm 5 vs $58 \pm 9 \% ; p>0.05$; combined data from three NORM and two CSH neurons), suggesting no discernable desensitization of adrenoreceptors in this protocol. Bath application the $\alpha$-adrenoreceptor antagonist phentolamine $(10 \mu \mathrm{M})$ did not significantly alter the amplitudes of eEPSCs in neurons from both groups ( $97 \pm 5 \%$ of control; from four NORM neurons and three CSH neurons), suggesting no tonic activation NTS $\alpha$-adrenoreceptors in our preparation. Phentolamine nearly abolished NE-mediated inhibition of eEPSCs in both NORM (41 $\pm 8 \%$ vs $6 \pm 5 \% ; n=3 ; p<0.05)$ and CSH $(73 \pm 18$ vs $8 \pm 8 \% ; n=3 ; p<0.05)$ neurons (Fig. $6 B)$. These data suggest that NE inhibition in the NTS is primarily mediated by $\alpha$-adrenoreceptors.

We further tested the effect of the $\beta$-adrenoreceptor antagonist propranolol using the same protocol. Propranolol $(10 \mu \mathrm{M})$ had no significant effect on eEPSCs ( $99 \pm 3 \%$ of control; combined data from four NORM neurons and three CSH neurons), and NE-mediated inhibition of eEPSCs in both NORM and CSH neurons ( $99 \pm 10 \%$ of NE alone; $p>0.05$; combined data from three NORM neurons and three CSH neurons). These data suggest that there was no tonic activation of NTS 
$\beta$-adrenoreceptors in our preparation, and $\beta$-adrenoreceptors play only a minor role in mediating NE inhibition of eEPSCs in the NTS in our preparation.

\section{$\mathrm{CSH}$ has different effect on the function} of NTS $\alpha 1$ - and $\alpha 2$-adrenoreceptors The relative role of $\alpha 1$ - and $\alpha 2$ adrenoreceptors in NE-mediated inhibition of eEPSCs in the NTS was examined. The $\alpha 1$-adrenoreceptor agonist phenylephrine $\left(\begin{array}{ll}40 & \mu \mathrm{M}\end{array}\right)$ and the $\alpha 2$ adrenoreceptor agonist clonidine $(3 \mu \mathrm{M})$ both inhibited eEPSCs (Fig. 7A). However, the effect of CSH on the inhibition mediated by these two $\alpha$-adrenoreceptors was different (Fig. 7B). CSH attenuated phenylephrine inhibition of eEPSCs $(p<0.05)$ but enhanced clonidine inhibition of eEPSCs $(p<0.05)$.

In second-order NTS neurons, coapplication of $10 \mu \mathrm{M}$ NE and the $\alpha 2$ adrenoreceptor antagonist yohimbine significantly attenuated NE-mediated inhibition of eEPSCs (Fig. 8A). Yohimbine itself did not significantly change the amplitudes of eEPSCs (NORM, $100 \pm 2 \%$ of control, $n=6$; CSH, $99 \pm 2 \%$ of control, $n=5$ ), again suggesting no tonic activation of NTS $\alpha 2$-adrenoreceptor in our preparation. In NORM neurons $(n=8)$, yohimbine reduced NE-mediated inhibition of eEPSCs from $42 \pm 7$ to $14 \pm 2 \%$, a $61 \pm 8 \%$ attenuation. In $\mathrm{CSH}$ neurons $(n=5)$, yohimbine reduced NE-mediated inhibition of eEPSCs from $63 \pm 9$ to $16 \pm$ $8 \%$, an attenuation of $76 \pm 11 \%$ (Fig. $8 B$, repeated). There was a significant difference in baseline NEmediated inhibition between the two groups $(p<0.01)$. There was no significant difference between NORM and CSH neurons in the NE-mediated inhibition that remained after blocking $\alpha 2$ adrenoreceptors with yohimbine.

In a separate group of neurons, NE $(10 \mu \mathrm{M})$ and yohimbine were applied simultaneously without previous application of NE alone to ensure that the antagonist effect was not altered by previous exposure to NE. In this protocol, the NE-mediated inhibition remaining after blocking $\alpha 2$-adrenoreceptors with yohimbine was not different between NORM neurons $(20 \pm 4 \%$; $n=4)$ and CSH neurons ( $22 \pm 5 \% ; n=7$ ) (Fig. $8 B$, single). No difference was observed in NE inhibition comparing protocols in which antagonist effects were measured in the absence of previous exposure to NE or after previous exposure to NE. The data from these two protocols strongly suggests that, although both $\alpha 1$ - and $\alpha 2$-adrenoreceptors mediate NE inhibition in the NTS, the enhanced NE inhibition of eEPSCs observed after CSH is primarily mediated by $\alpha 2$-adrenoreceptors.

\section{Discussion}

We report two significant new findings. First, exposure to $\mathrm{CSH}$ enhances the amplitude of the glutamatergic EPSC evoked by peripheral afferent stimulation in NTS neurons receiving monosynaptic arterial chemoreceptor inputs. Both presynaptic and postsynaptic factors appear to contribute to the enhanced eEPSC.
Second, presynaptic inhibition of glutamate release from afferents to these same neurons by $\alpha 2$-adrenoreceptors is enhanced after chronic exposure to hypoxia.

We found that the amplitude of eEPSCs was greater in NTS neurons from CSH rats compared with NORM rats. This is the result of an increased postsynaptic sensitivity to excitatory amino acids as demonstrated by our puff applications of glutamate. Because these applications were performed in the presence of NMDA receptor blockade, it is likely that this increased sensitivity reflects alterations in the AMPA receptor. In fact, we observed increased levels of AMPA receptor GluR2 subunit, but not GluR1 subunit, in the NTS after CSH exposure. Previous study by our laboratory provided electrophysiological evidence suggesting that the AMPA receptors on NTS neurons receiving monosynaptic arterial chemoreceptor inputs contain GluR2 subunits (de Paula et al., 2007). Possible mechanisms underlying increased expression and/or sensitivity of AMPA receptors include hypoxia-induced activation of multiple kinases, leading to phosphorylation of AMPA receptor subunits, activity-dependent changes in AMPA receptor subunit composition, and increased expression and/or trafficking of AMPA receptors (Gozal et al., 1998, 2000; Esteban et al., 2003; Derkach et al., 2007; Schmid et al., 2008). Along with enhanced excitation of carotid bodies after exposure to CSH (Prabhakar and Jacono, 2005; Powell, 2007), these data suggest that both peripheral and central neural mech- 


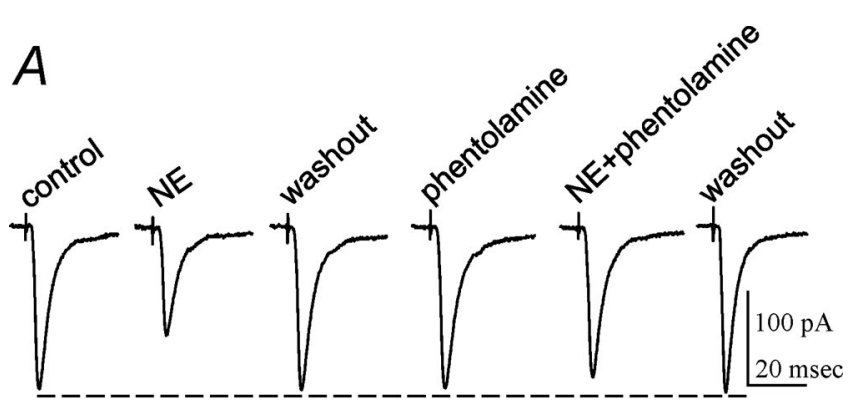

$B$

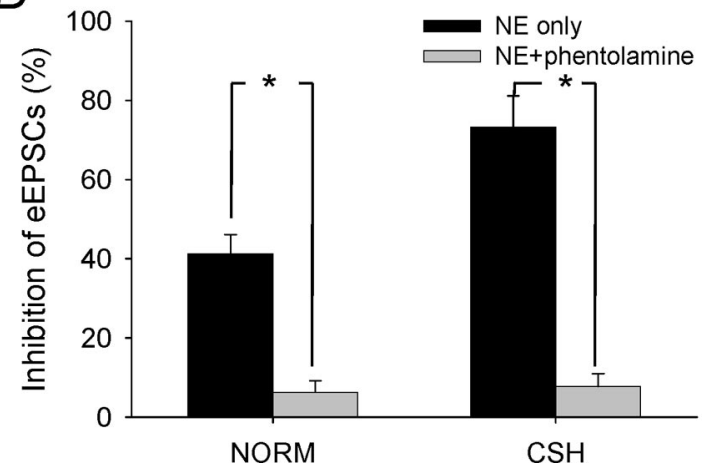

Figure 6. NE effect in the NTS is mediated by $\alpha$-adrenoreceptors. $\boldsymbol{A}$, Raw data showing that the $\alpha$-adrenoreceptor antagonist phentolamine (10 $\mu \mathrm{m}$ ) blocked the inhibition of eEPSCs by 10 $\mu \mathrm{M}$ NE. $\boldsymbol{B}$, Phentolamine blocked NE-mediated inhibition of eEPSCs in both NORM and CSH neurons (both $n=3$ ). ${ }^{*} p<0.05$, compared with NE alone.

anisms contribute to enhanced response to acute hypoxia after exposure to CSH (Powell et al., 2000).

We also found alterations in glutamate release after exposure to $\mathrm{CSH}$. The frequency of mEPSCs was reduced, suggesting a reduction in release probability. This may not seem consistent with our finding of an increased eEPSC after exposure to CSH. However, it is important to keep in mind that the eEPSC reflects synchronous activation of peripheral afferent inputs to the cell, whereas mEPSCs reflect spontaneous release from any glutamatergic terminals in close proximity to the cell. As such, mEPSCs reflect potential glutamate release from not only peripheral afferents but also inputs from other central sites and/or local interneurons. The modulation of vesicular release mechanisms can differ depending on whether the release sites are synaptic or ectopic (Matsui and Jahr, 2004). The eEPSC may be representative of release from synaptic sites, whereas mEPSCs may reflect, at least in part, ectopic release.

A recent report found that exposure to chronic intermittent hypoxia $(\mathrm{CIH})$ depressed eEPSCs in NTS neurons studied in a brain slice (Kline et al., 2007). The authors suggested that CIHinduced depression of EPSCs is mediated by a presynaptic mechanism without the apparent involvement of any postsynaptic changes. In this report, the absence of postsynaptic changes was inferred from the lack of change in the amplitude of mEPSCs. In contrast, another report shows that $\mathrm{CIH}$ enhanced neuronal response to exogenous application of AMPA in enzymatically dissociated NTS second-order neurons without a significant change in $\mathrm{EC}_{50}$ (de Paula et al., 2007). In our present study, we also found no changes in the amplitude of mEPSCs after CSH, but direct testing of postsynaptic sensitivity to glutamate revealed a different story. Responses to exogenous applications of agonist could include receptors not normally activated by synaptically released glutamate, or, as discussed above, analysis of spontaneous trans-
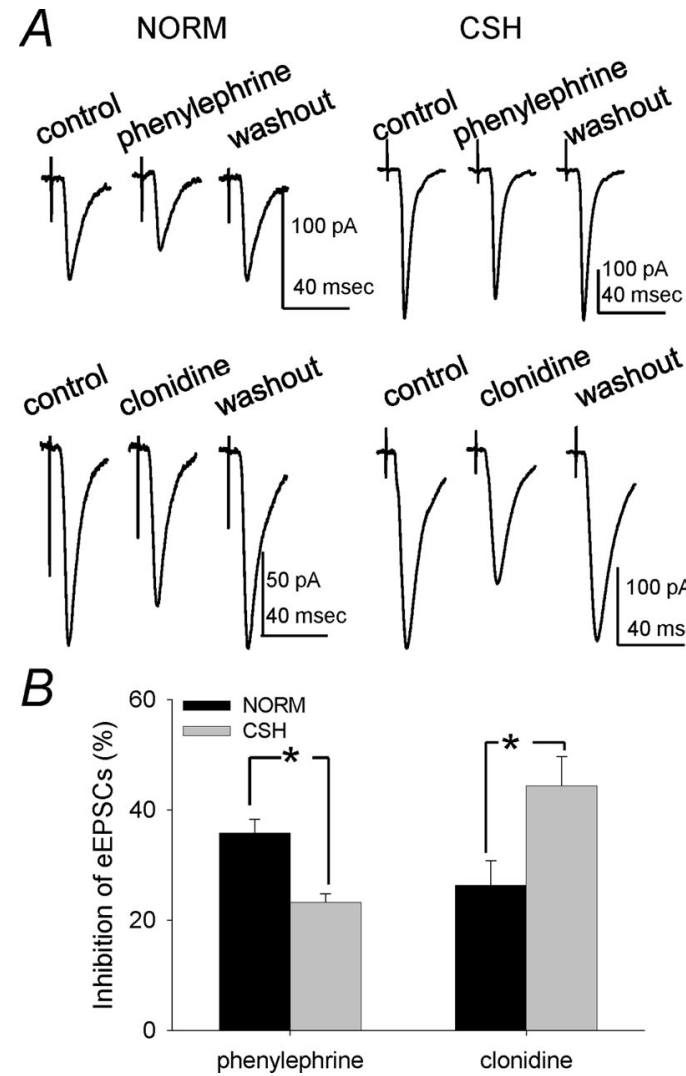

Figure 7. $\quad$ CSH effect on NTS $\alpha 1$ - and $\alpha 2$-adrenoreceptors. $\boldsymbol{A}$, Raw data showing that both the $\alpha 1$-adrenoreceptor agonist phenylephrine (40 $\mu \mathrm{m}$ ) and the $\alpha 2$-adrenoreceptor agonist clonidine $(3 \mu \mathrm{m})$ inhibited eEPSCs in both NORM and CSH neurons. $\boldsymbol{B}$, CSH significantly attenuated phenylephrine-mediated inhibition of eEPSCs ( $36 \pm 2 \%, n=11$ vs $26 \pm 4 \%, n=6$ ) and enhanced clonidine-mediated inhibition of eEPSCs $(23 \pm 2 \%, n=5$ vs $44 \pm 5 \%, n=4) .{ }^{*} p<$ 0.05 .

mitter release may include inputs not derived from the primary afferent. Nonetheless, more work needs to be done to differentiate changes in presynaptic and postsynaptic function after chronic exposures to both sustained and intermittent hypoxia.

Our current results demonstrated that NE inhibition of eEPSCs is mediated by both presynaptic $\alpha 1-$ and $\alpha 2$ adrenoreceptors, and this inhibitory effect is enhanced after $\mathrm{CSH}$. Furthermore, presynaptic $\alpha 2$-adrenoreceptors mediate the CSHenhanced NE inhibition. These results extend our previous investigation of presynaptic $\alpha 1$-adrenoreceptors in modulating synaptic transmission of arterial chemoreceptor inputs in the NTS (Zhang and Mifflin, 2007) and reveal a previously unrecognized central neural adaptive response to CSH. Our results are consistent with previous in vivo studies demonstrating inhibitory effects of NE mediated by both $\alpha 1$ - and $\alpha 2$-adrenoreceptors in the NTS (De Jong, 1974; Moore and Guyenet, 1983; Feldman and Moises, 1987; Feldman and Moises, 1988; Feldman and Felder, 1989a,b; Silva de Oliveira et al., 2007). However, one study reported that microinjection of an $\alpha 2$-adrenoreceptor antagonist into the NTS attenuated the arterial chemoreflex (Hayward, 2001). Such a result seems contradictory to our findings. We have observed that activation of $\alpha 2$-adrenoreceptors can also inhibit IPSCs in the NTS via a presynaptic mechanism (W. Zhang and S. W. Mifflin, unpublished observation). NE inhibits GABAergic synaptic transmission via presynaptic $\alpha 2$-adrenoreceptors in other central neural sites (Han et al., 2002; Li et al., 2005; Hirono and Obata, 2006). Thus, the neuronal responses in the NTS will 

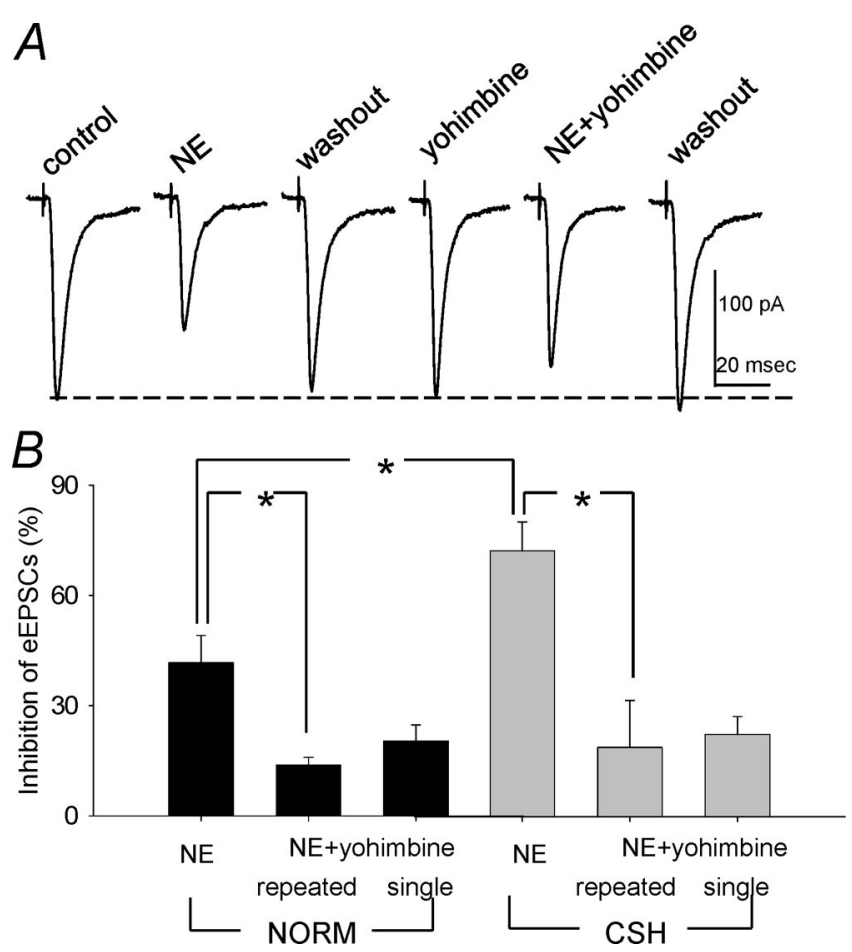

Figure 8. The role of $\alpha 2$-adrenoreceptors in NE inhibition in the NTS. $\boldsymbol{A}$, Raw data showing that the $\alpha 2$-adrenoreceptor antagonist yohimbine (10 $\mu \mathrm{M})$ significantly attenuated NE (10 $\mu \mathrm{m}$ ) inhibition of eEPSCs. $\boldsymbol{B}$, Group data showing that NE inhibition in both CSH and NORM neurons is blocked by yohimbine. After treatment with yohimbine, there was no significant difference between groups in the remaining NE inhibition, suggesting that $\alpha 2$ adrenoreceptors primarily mediate the enhanced NE inhibition of eEPSCS after CSH. Repeated NE plus yohimbine represents data from neurons that received coapplication of NE and yohimbine after first being exposed to NE alone (repeated-application protocol), and single NE plus yohimbine represents data from neurons that only received coapplication of NE and yohimbine (single-application protocol). ${ }^{*} p<0.05$.

depend on the balance between excitatory glutamatergic inputs and inhibitory GABAergic inputs. This could be one possible mechanism underlying the inhibitory effect of $\alpha 2$ adrenoreceptor antagonist in arterial chemoreflexes (Hayward, 2001). Future studies will be needed to investigate NE-mediated modulation of IPSCs in the NTS and the impact of CSH.

This current study established a major role for $\alpha 2$ adrenoreceptors in mediating $\mathrm{CSH}$-induced alterations of NE inhibition in the NTS. This could represent a neural adaptive response to $\mathrm{CSH}$ with potential physiological significance. Increased chemoreceptor discharge after CSH (Prabhakar and Jacono, 2005; Powell, 2007) should result in increased arterial chemoreceptor inputs to the NTS. Supporting this is the observation that the respiratory response to acute hypoxia is enhanced after CSH (Powell et al., 2000). Our study also found attenuated frequency-dependent depression of eEPSCs in brainstem slices collected from CSH rats, resulting in larger-amplitude eEPSCs at any given tractus stimulation frequency, which suggests increased glutamate release from presynaptic afferent terminals. Enhanced presynaptic $\alpha 2$-adrenoreceptor-mediated inhibition of glutamate release from afferent terminals might be an adaptive mechanism to limit excitotoxic damage and maintain neuronal function. $\mathrm{CSH}$ enhanced $\alpha 2$-adrenoreceptor-mediated inhibition of neuronal excitability has been reported in the locus ceruleus (Chang et al., 2006). This postsynaptic change is correlated with an increased number of neuronal $\alpha 2$-receptor binding sites in locus ceruleus. There might be a similar upregulation of presynaptic $\alpha 2$-adrenoreceptors in the NTS after CSH.
Under what conditions do NTS adrenoceptors modulate chemoreceptor afferent integration? $\mathrm{CSH}$ increased the activity of tyrosine hydroxylase, the rate-limiting enzyme in catecholamine biosynthesis, in the NTS, including the A2 cell group (Soulier et al., 1995; Pépin et al., 1996), the ventrolateral medulla (Schmitt et al., 1993), and the locus ceruleus (Schmitt et al., 1993). Furthermore, CSH increased NE turnover in A2 cell group but decreased that in A5 cell group and locus ceruleus with no significant effect in A1 cell group (Soulier et al., 1992). These noradrenergic structures appear to be involved in arterial chemoreflex pathways because systemic hypoxia or carotid sinus nerve stimulation increases c-fos expression in these structures (Erickson and Millhorn, 1994; Smith et al., 1995; Teppema et al., 1997; Buller et al., 1999). Arterial chemoreceptor stimulation evoked neuronal discharge in these noradrenergic structures (Li et al., 1992; Guyenet et al., 1993), suggesting their active roles in modulating arterial chemoreflexes. In vivo studies have demonstrated that excitation or inhibition of these noradrenergic neural structures can modulate cardiorespiratory responses to arterial chemoreceptor stimulation (Koshiya and Guyenet, 1994a,b; Pérez et al., 1998; Hayward, 2001). These data suggest that activation of central noradrenergic neural structures during arterial chemoreceptor stimulation could release NE and modulate synaptic transmission in the NTS. Our current data cannot evaluate the contribution of different noradrenergic neural structures. The A2 cell group might be an important source of NE because it is located within the NTS and receives increased afferent inputs after $\mathrm{CSH}$. At least some A2 neurons are second-order neurons of arterial chemoreceptors (Kawai and Senba, 1999) (Zhang and Mifflin, unpublished observation). These neurons may play a crucial role in neural adaptations to $\mathrm{CSH}$.

In summary, our current project investigated one inhibitory mechanism in the NTS after CSH. Although the role of NE in arterial chemoreflexes requires additional investigation (McCrimmon et al., 1983; Joseph et al., 1998; Schreihofer and Guyenet, 2000), we suggest that enhanced NE inhibition of glutamate release is a neural adaptive mechanism in response to increased afferent inputs during CSH. CSH results in enhanced excitation of carotid bodies (Prabhakar and Jacono, 2005; Powell, 2007), which may initiate changes in central synaptic transmission such as increased amplitude of solitary tract-evoked EPSCs and attenuated frequency-dependent depression of eEPSCs reported here. Tissue hypoxia may also contribute to the initiation and/or maintenance of these changes in synaptic transmission (Zhang et al., 2008). The synaptic integrative functions of the NTS will influence the flow of information downstream in the reflex pathway (Loewy, 1990; Mifflin, 1992). Alterations in NE inhibition could play a crucial role in neural plasticity of synaptic integration of arterial chemoreceptor inputs in the NTS.

\section{References}

Aoki C, Zemcik BA, Strader CD, Pickel VM (1989) Cytoplasmic loop of beta-adrenergic receptors: synaptic and intracellular localization and relation to catecholaminergic neurons in the nuclei of the solitary tracts. Brain Res 493:331-347.

Bailey TW, Jin YH, Doyle MW, Smith SM, Andresen MC (2006) Vasopressin inhibits glutamate release via two distinct modes in the brainstem. J Neurosci 26:6131-6142.

Buller KM, Smith DW, Day TA (1999) NTS catecholamine cell recruitment by hemorrhage and hypoxia. Neuroreport 10:3853-3856.

Chang KC, Yang JJ, Liao JF, Wang CH, Chiu TH, Hsu FC (2006) Chronic hypobaric hypoxia induces tolerance to acute hypoxia and up-regulation in alpha-2 adrenoceptor in rat locus coeruleus. Brain Res 1106:82-90.

Chen CY, Horowitz JM, Bonham AC (1999) A pre-synaptic mechanism 
contributes to depression of autonomic signal transmission in NTS. Am J Physiol Heart Circ Physiol 277:H1350-H1360.

Dashwood MR, Gilbey MP, Spyer KM (1985) The localization of adrenoceptors and opiate receptors in regions of the cat central nervous system involved in cardiovascular control. Neuroscience 15:537-551.

Day HE, Campeau S, Watson SJ Jr, Akil H (1997) Distribution of $\alpha_{1 a^{-}}, \alpha_{1 b^{-}}$ and $\alpha_{1 \mathrm{~d}^{-}}$-adrenergic receptor mRNA in the rat brain and spinal cord. J Chem Neuroanat 13:115-139.

De Jong W (1974) Noradrenaline: central inhibitory control of blood pressure and heart rate. Eur J Pharmacol 29:179-181.

de Paula PM, Tolstykh G, Mifflin S (2007) Chronic intermittent hypoxia alters NMDA and AMPA-evoked currents in NTS neurons receiving carotid body chemoreceptor inputs. Am J Physiol Regul Integr Comp Physiol 292:R2259-R2265.

Derkach VA, Oh MC, Guire ES, Soderling TR (2007) Regulatory mechanisms of AMPA receptors in synaptic plasticity. Nat Rev Neurosci 8:101-113.

Doyle MW, Andresen MC (2001) Reliability of monosynaptic sensory transmission in brain stem neurons in vitro. J Neurophysiol 85:2213-2223.

Erickson JT, Millhorn DE (1994) Hypoxia and electrical stimulation of the carotid sinus nerve induce Fos-like immunoreactivity within catecholaminergic and serotoninergic neurons of the rat brainstem. J Comp Neurol 348:161-182.

Esteban JA, Shi SH, Wilson C, Nuriya M, Huganir RL, Malinow R (2003) PKA phosphorylation of AMPA receptor subunits controls synaptic trafficking underlying plasticity. Nat Neurosci 6:136-143.

Feldman PD, Felder RB (1989a) Alpha-adrenergic influences on neuronal responses to visceral afferent input in the nucleus tractus solitarius. Neuropharmacology 28:1081-1087.

Feldman PD, Felder RB (1989b) $\alpha_{2}$-Adrenergic modulation of synaptic excitability in the rat nucleus tractus solitarius. Brain Res 480:190-197.

Feldman PD, Moises HC (1987) Adrenergic responses of baroreceptive cells in the nucleus tractus solitarii of the rat: a microiontophoretic study. Brain Res 420:351-361.

Feldman PD, Moises HC (1988) Electrophysiological evidence for $\alpha_{1}$ - and $\alpha_{2}$-adrenoceptors in solitary tract nucleus. Am J Physiol Heart Circ Physiol 254:H756-H762.

Glaum SR, Miller RJ (1995) Pre-synaptic metabotropic glutamate receptors modulate $\omega$-Conotoxin-GVIA-insensitive calcium channels in the rat medulla. Neuropharmacology 34:953-964.

Globus MY, Busto R, Dietrich WD, Martinez E, Valdés I, Ginsberg MD (1989) Direct evidence for acute and massive norepinephrine release in the hippocampus during transient ischemia. J Cereb Blood Flow Metab 9:892-896.

Gozal D, Gozal E, Simakajornboon N (2000) Signaling pathways of the acute hypoxic ventilatory response in the nucleus of the solitary tract. Respir Physiol 121:209-221.

Gozal E, Roussel AL, Holt GA, Gozal L, Gozal YM, Torres JE, Gozal D (1998) Protein kinase $\mathrm{C}$ modulation of ventilatory responses to hypoxia in nucleus tractus solitarii of conscious rats. J Appl Physiol 84:1982-1990.

Guyenet PG (2000) Neural structures that mediate sympatho-excitation during hypoxia. Respir Physiol 121:147-162.

Guyenet PG, Koshiya N, Huangfu D, Verberne AJ, Riley TA (1993) Central respiratory control of A5 and A6 pontine noradrenergic neurons. Am J Physiol Regul Integr Comp Physiol 264:R1035-R1044.

Han SK, Chong W, Li LH, Lee IS, Murase K, Ryu PD (2002) Noradrenaline excites and inhibits GABAergic transmission in parvocellular neurons of rat hypothalamic paraventricular nucleus. J Neurophysiol 87:2287-2296.

Hayward LF (2001) Evidence for $\alpha$-2 adrenoreceptor modulation of arterial chemoreflexes in the caudal solitary nucleus of the rat. Am J Physiol Regul Integr Comp Physiol 281:R1464-R1473.

Hirono M, Obata K (2006) $\alpha$-Adrenoceptive dual modulation of inhibitory GABAergic inputs to Purkinje cells in the mouse cerebellum. J Neurophysiol 95:700-708.

Ilyinsky O, Mifflin S (2005) Chronic hypoxia abolishes expiratory prolongation following carotid sinus nerve stimulation in the anesthetized rat. Respir Physiol Neurobiol 146:269-277.

Ilyinsky O, Tolstykh G, Mifflin S (2003) Chronic hypoxia abolishes posthypoxia frequency decline in the anesthetized rat. Am J Physiol Regul Integr Comp Physiol 285:R1322-R1330.

Jones LS, Gauger LL, Davis JN (1985) Anatomy of brain alpha 1-adrenergic receptors: in vitro autoradiography with $\left[{ }^{125} \mathrm{I}\right]$-heat. J Comp Neurol 231:190-208.

Joseph V, Dalmaz Y, Cottet-Emard JM, Pequignot JM (1998) Dexamethasone's influence on tyrosine hydroxylase activity in the chemoreflex pathway and on the hypoxic ventilatory response. Pflugers Arch 435:834-839.

Kawai Y, Senba E (1999) Electrophysiological and morphological characterization of cytochemically-defined neurons in the caudal nucleus of tractus solitarius of the rat. Neuroscience 89:1347-1355.

Kline DD, Ramirez-Navarro A, Kunze DL (2007) Adaptive depression in synaptic transmission in the nucleus of the solitary tract after in vivo chronic intermittent hypoxia: evidence for homeostatic plasticity. J Neurosci 27:4663-4673.

Koshiya N, Guyenet PG (1994a) Role of the pons in the carotid sympathetic chemoreflex. Am J Physiol Regul Integr Comp Physiol 267:R508-R518.

Koshiya N, Guyenet PG (1994b) A5 noradrenergic neurons and the carotid sympathetic chemoreflex. Am J Physiol Regul Integr Comp Physiol 267:R519-R526.

Li DP, Atnip LM, Chen SR, Pan HL (2005) Regulation of synaptic inputs to paraventricular-spinal output neurons by $\alpha_{2}$ adrenergic receptors. J Neurophysiol 93:393-402.

Li YW, Gieroba ZJ, Blessing WW (1992) Chemoreceptor and baroreceptor responses of Al area neurons projecting to supraoptic nucleus. Am J Physiol Regul Integr Comp Physiol 263:R310-R317.

Lipton P (1999) Ischemic cell death in brain neurons. Physiol Rev 79:1431-1568.

Loewy AD (1990) Central autonomic pathways. In: Central regulation of autonomic functions (Loewy AD, Spyer KM, eds), pp 88-103. Oxford: New York.

Matsui K, Jahr CE (2004) Differential control of synaptic and ectopic vesicular release of glutamate. J Neurosci 24:8932-8939.

McCrimmon DR, Dempsey JA, Olson EB Jr (1983) Effect of catecholamine depletion on ventilatory control in unanesthetized normoxic and hypoxic rats. J Appl Physiol 55:522-528.

Mifflin SW (1992) Arterial chemoreceptor input to nucleus tractus solitarius. Am J Physiol Regul Integr Comp Physiol 263:R368-R375.

Miles R (1986) Frequency dependence of synaptic transmission in nucleus of the solitary tract in vitro. J Neurophysiol 55:1076-1090.

Moore SD, Guyenet PG (1983) Alpha-receptor mediated inhibition of A2 noradrenergic neurons. Brain Res 276:188-191.

Nakai T, Milusheva E, Baranyi M, Uchihashi Y, Satoh T, Vizi ES (1999) Excessive release of $\left[{ }^{3} \mathrm{H}\right]$ noradrenaline and glutamate in response to simulation of ischemic conditions in rat spinal cord slice preparation: effect of NMDA and AMPA receptor antagonists. Eur $J$ Pharmacol 366:143-150.

Pépin JL, Lévy P, Garcin A, Feuerstein C, Savasta M (1996) Effects of longterm hypoxia on tyrosine hydroxylase protein content in catacholaminergic rat brainstem areas: a quantitative autoradiographic study. Brain Res 733:1-8.

Perego C, Gatti S, Vetrugno GC, Marzatico F, Algeri S (1992) Correlation between electroencephalogram isoelectric time and hippocampal norepinephrine levels, measured by microdialysis, during ischemia in rats. J Neurochem 59:1257-1262.

Pérez H, Ruiz S, Laurido C, Hernández A (1998) Locus coeruleus-mediated inhibition of chemosensory responses in the rat nucleus tractus solitarius is mediated by $\alpha_{2}$-adrenoreceptors. Neurosci Lett 249:37-40.

Powell FL (2007) The influence of chronic hypoxia upon chemoreception. Respir Physiol Neurobiol 157:154-161.

Powell FL, Huey KA, Dwinell MR (2000) Central nervous system mechanisms of ventilatory acclimatization to hypoxia. Respir Physiol 121:223-236.

Prabhakar NR, Jacono FJ (2005) Cellular and molecular mechanisms associated with carotid body adaptations to chronic hypoxia. High Alt Med Biol 6:112-120.

Scheuer DA, Zhang J, Toney GM, Mifflin SW (1996) Temporal processing of aortic nerve evoked activity in the nucleus of the solitary tract. J Neurophysiol 76:3750-3757.

Schild JH, Clark JW, Canavier CC, Kunze DL, Andresen MC (1995) Afferent synaptic drive of rat medial nucleus tractus solitarius neurons: $d y-$ namic simulation of graded vesicular mobilization, release, and nonNMDA receptor kinetics. J Neurophysiol 74:1529-1548.

Schmid A, Hallermann S, Kittel RJ, Khorramshahi O, Frölich AM, Quentin C, Rasse TM, Mertel S, Heckmann M, Sigrist SJ (2008) Activity-dependent 
site-specific changes of glutamate receptor composition in vivo. Nat Neurosci 11:659-666.

Schmitt P, Pequignot J, Garcia C, Pujol JF, Pequignot JM (1993) Regional specificity of the long-term regulation of tyrosine hydroxylase in some catecholaminergic rat brainstem areas. I. Influence of long-term hypoxia. Brain Res 611:53-60.

Schmitt P, Soulier V, Péquignot JM, Pujol JF, Denavit-Saubié M (1994) Ventilatory acclimatization to chronic hypoxia: relationship to noradrenaline metabolism in the rat solitary complex. J Physiol 477:331-337.

Schreihofer AM, Guyenet PG (2000) Sympathetic reflexes after depletion of bulbospinal catecholaminergic neurons with anti-D $\beta \mathrm{H}$-saporin. Am J Physiol Regul Integr Comp Physiol 279:R729-R742.

Silva de Oliveira LC, Bonagamba LG, Machado BH (2007) Noradrenergic inhibitory modulation in the caudal commissural NTS of the pressor response to chemoreflex activation in awake rats. Auton Neurosci 136:63-68.

Smith DW, Buller KM, Day TA (1995) Role of ventrolateral medulla catecholamine cells in hypothalamic neuroendocrine cell responses to systemic hypoxia. J Neurosci 15:7979-7988.

Soulier V, Cottet-Emard JM, Pequignot J, Hanchin F, Peyrin L, Pequignot JM (1992) Differential effects of long-term hypoxia on norepinephrine turnover in brain stem cell groups. J Appl Physiol 73:1810-1814.
Soulier V, Dalmaz Y, Cottet-Emard JM, Kitahama K, Pequignot JM (1995) Delayed increase of tyrosine hydroxylation in the rat A2 medullary neurons upon long-term hypoxia. Brain Res 674:188-195.

Teppema LJ, Veening JG, Kranenburg A, Dahan A, Berkenbosch A, Olievier C (1997) Expression of $c$-fos in the rat brainstem after exposure to hypoxia and to normoxic and hyperoxic hypercapnia. J Comp Neurol 388:169-190.

Tolstykh G, Belugin S, Mifflin S (2004) Responses to GABA $A_{A}$ receptor activation are altered in NTS neurons isolated from chronic hypoxic rats Brain Res 1006:107-113.

Young WS 3rd, Kuhar MJ (1980) Noradrenergic $\alpha_{1}$ and $\alpha_{2}$ receptors: light microscopic autoradiographic localization. Proc Natl Acad Sci U S A 77:1696-1700.

Zhang W, Mifflin SW (2007) Modulation of synaptic transmission to second-order peripheral chemoreceptor neurons in caudal nucleus tractus solitarius by $\alpha_{1}$-adrenoreceptors. J Pharmacol Exp Ther 320:670 -677.

Zhang W, Carreño FR, Cunningham JT, Mifflin SW (2008) Chronic sustained and intermittent hypoxia reduce function of ATP-sensitive potassium channels in nucleus of the solitary tract. Am J Physiol Regul Integr Comp Physiol 295:R1555-R1562.

Zucker RS, Regehr WG (2002) Short-term synaptic plasticity. Annu Rev Physiol 64:355-405. 